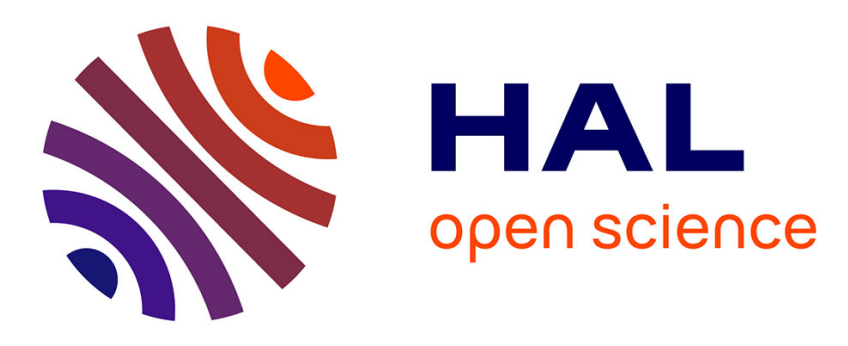

\title{
Yttria - stabilized zirconia thin films deposited by pulsed-laser deposition and magnetron sputtering
} Hervé Hidalgo, Ekaterina Rezugina, Eric Millon, Anne Lise Thomann, Jacky Mathias, Chantal Boulmer-Leborgne, Thierry Sauvage, Pascal Brault

\section{- To cite this version:}

Hervé Hidalgo, Ekaterina Rezugina, Eric Millon, Anne Lise Thomann, Jacky Mathias, et al.. Yttria stabilized zirconia thin films deposited by pulsed-laser deposition and magnetron sputtering. Surface and Coatings Technology, 2011, 205, pp.4495-4499. 10.1016/j.surfcoat.2011.03.077 . hal-00593632

\section{HAL Id: hal-00593632 \\ https://hal.science/hal-00593632}

Submitted on 16 May 2011

HAL is a multi-disciplinary open access archive for the deposit and dissemination of scientific research documents, whether they are published or not. The documents may come from teaching and research institutions in France or abroad, or from public or private research centers.
L'archive ouverte pluridisciplinaire HAL, est destinée au dépôt et à la diffusion de documents scientifiques de niveau recherche, publiés ou non, émanant des établissements d'enseignement et de recherche français ou étrangers, des laboratoires publics ou privés. 


\title{
Yttria - stabilized zirconia thin films deposited by pulsed-laser deposition and magnetron sputtering
}

H. Hidalgo a , E. Reguzina ${ }^{\mathrm{a}}$, E. Millon ${ }^{\mathrm{a}}$, A-L. Thomann ${ }^{\mathrm{a}}$, J. Mathias ${ }^{\mathrm{a}}$, C. Boulmer-Leborgne ${ }^{\mathrm{a}}$, T. Sauvage ${ }^{\mathrm{b}}$, P. Brault ${ }^{\mathrm{a}}$

a GREMI, UMR CNRS 6606 Université d'Orléans, 14 rue d'Issoudun 45067 Orléans, France

b CEMHTI, UPR CNRS 3079, 3A rue de la Férollerie, 45071 Orléans, France

\begin{abstract}
:
Yttria-stabilized zirconia (YSZ, $\mathrm{ZrO}_{2}: \mathrm{Y}_{2} \mathrm{O}_{3}$ ) was deposited on (100) silicon by two physical vapor deposition techniques: pulsed laser deposition (PLD) and reactive magnetron sputtering (RMS). PLD thin films were grown on silicon substrates at $500^{\circ} \mathrm{C}$ from the ablation of a 8YSZ ceramic target by a KrF excimer laser. RMS thin films were obtained by direct current magnetron sputtering of a $\mathrm{Zr} / \mathrm{Y}$ metallic target in an oxygen/argon atmosphere. The deposition rate of the PLD technique using an UV excimer laser delivering pulses at a repetition rate of $40 \mathrm{~Hz}$ was found two orders of magnitude lower than the RMS method one. Both techniques led to the growth of crystalline films with a (111) preferential orientation. PLD films were dense and featureless whereas RMS ones exhibited well defined but compact columnar structure. Growth of a YSZ film of about $1 \mu \mathrm{m}$ covering a rough and porous commercial anode support (NiO-YSZ cermet) was successfully carried out with both methods.
\end{abstract}

Keywords: Solid oxide fuel cell; Yttria stabilized zirconia; thin film growth; Pulsed laser deposition; reactive magnetron sputtering; porous substrate 


\section{Introduction}

Yttria-stabilized zirconia (YSZ) material is one of the most widespread advanced materials. It can be used in various fields: microelectronics as buffer layer of IBCO superconducting films [1] or dielectric gate in the integrated circuits [2]; as biocompatible and hard material in hip replacement [3] or artificial teeth [4]; as thermal-barrier coatings (TBCs) and protective coatings for its high temperature superior thermo-mechanical behaviour in turbine blade or other engine components [5]; as gas sensor for automotive exhaust applications [6]

YSZ has played an important role in the development of SOFC (Solid Oxide Fuel Cell), and it is nowadays widely used as an electrolyte. The electrolyte of SOFC must be a solid oxide with a high ionic conductivity and a high electronic resistivity. In addition, it must be chemically stable at high temperature in oxidizing and reducing atmospheres, chemically and mechanically compatible with the other cell components and gas tight. Whereas the bulk tetragonal zirconia is a poor ionic conductor, the high temperature cubic phase exhibits a very high ionic conductivity. Moreover, this cubic phase can be stabilised at low temperature by the incorporation of yttria. The obtained solid solution of cubic form induces the creation of $\mathrm{O}^{2-}$ vacancies according to the substitution of $\mathrm{Zr}^{4+}$ by $\mathrm{Y}^{3+}$ in the cationic network. For the bulk material, the ionic conductivity reaches a maximum for an yttria content in the $\mathrm{ZrO}_{2}: \mathrm{Y}_{2} \mathrm{O}_{3}$ solid solution between 8 and $12 \%$ (8YSZ-12YSZ) [7].

Nevertheless, these ionic conductive properties are efficient enough only at high temperature $\left(800-1000^{\circ} \mathrm{C}\right)$ which leads to thermal or mechanical degradation of the cell materials which drastically limits its lifetime. The reduction of the operating temperature below $700^{\circ} \mathrm{C}$ may be sufficient to solve this problem. Among the possible concepts to reach this goal (optimization of materials properties, manufacturing methods or design of cell components), the most promising way is to reduce the thickness of the cell and, in particular, that of the 
electrolyte. Thus, for some applications, such as SOFC, there is a great interest to synthesize high quality YSZ thin films.

The most widespread fabrication processes of YSZ films include a sintering step to obtain a thickness from 20 to $100 \mu \mathrm{m}$. Thinner films can be produced by thin film processes such as physical or chemical vapour deposition (PVD, CVD), plasma enhanced CVD (PECVD), sol-gel method, electrochemical vapour deposition, suspension or atmospheric plasma spraying [8-9]. All these techniques allows for the synthesis of 0.1 to $20 \mu \mathrm{m}$ thick YSZ layers. In that sense, pulsed-laser deposition (PLD) [10] and reactive magnetron sputtering (RMS) [11] are promising to produce YSZ thin films. PLD is known for its ability to grow adherent, crystalline thin $(0.001-1 \mu \mathrm{m})$ films respecting the stoichiometry of the target. RMS provides adherent thicker coatings $(0.01-10 \mu \mathrm{m})$ but the chemical composition and the crystallinity of the coating are depending on the deposition conditions.

In this paper, a comparative study of YSZ thin films obtained by PLD and RMS is reported. First, YSZ films are grown onto silicon substrate in experimental conditions leading to films with the best quality by each technique. Their morphological and structural features are investigated and compared. In a second step, YSZ films are deposited by PLD and RMS on a commercial NiO-YSZ anode (SOFC application). Since this material is rough and porous, it is of particular importance to check the morphology and the conformity of the deposited films This is a first step to fulfil for ensuring good properties of the films and, in the present example, evidencing the possibility to use PVD YSZ thin films as electrolyte in SOFC structures.

\section{Experimental}

PLD experiments were performed in the equipment described in reference [12] which offers the possibility to work with either one laser beam or two lasers in cross-beam configuration 
(cross-beam PLD). In the present study, the classical PLD geometry was used: only a single beam delivered by a KrF excimer laser (Lambda Physics Compex: wavelength $248 \mathrm{~nm}$, pulse duration $27 \mathrm{~ns}$, repetition rate $40 \mathrm{~Hz}$ ) was focused (1.5 mm diameter) by 2 cylindrical $\mathrm{MgF}_{2}$ lenses (respectively 12.5 and $22.5 \mathrm{~cm}$ semi-axes) on a rotating $5.08 \mathrm{~cm}$ (2")-diameter 8YSZ sintered ceramic target to reach an energy density (fluence) of about $2 \mathrm{~J} . \mathrm{cm}^{-2}$. The incidence angle of the laser beam on the target was $30^{\circ}$. Before deposition, the stainless steel deposition chamber was evacuated down to $10^{-4} \mathrm{~Pa}$ using a turbo molecular pump. The substrates were fixed with silver paste on a substrate holder located $6 \mathrm{~cm}$ away from the target. The surface temperature was raised up to $500^{\circ} \mathrm{C}$ by a resistive heater. Before deposition, the target was irradiated by the laser beam in order to remove surface impurities and to prevent droplet ejection. Meanwhile, the samples were protected by a stainless steel shutter. During deposition, the oxygen pressure in the PLD chamber can be controlled in the $10^{-4}$ to $100 \mathrm{~Pa}$ range in order to grow YSZ film with the correct oxygen stoichiometry. According to preliminary studies, the oxygen pressure was kept at $10^{-4} \mathrm{~Pa}$. After the deposition step, the samples were cooled down to room temperature with the same oxygen pressure.

Magnetron sputtering experiments were performed in a stainless steel deposition chamber using a 2"- planar magnetron (Thin Film Consulting ION'C-2") powered by a direct current power supply (A2E technologies - $1000 \mathrm{~V}, 2 \mathrm{~A}$ ): the current intensity was set at $1 \mathrm{~A}$, which induced a bias voltage value of $370 \mathrm{~V}$. A vacuum-melted metallic zirconium-yttrium target (82/18 \%wt, NEYCO 99.5\%) was clamped onto the cathode. A 5 cm-long chimney was used to avoid deposition everywhere in the chamber. Before deposition, the chamber was evacuated down to $10^{-4} \mathrm{~Pa}$ using a turbo molecular pump; the pressure during deposition was 1 Pa. Argon (Air Liquide 99.9995\%) and oxygen (Air Liquide 99.9995\%) flow rates were monitored by two mass flow controllers respectively at 4 and $2 \mathrm{sccm}$. In this range of oxygen to argon flow rate ratio, the deposition mode is still metallic [13] in our conditions. Indeed, 
the deposition conditions were chosen to achieve both high deposition rate and high oxidation level of the films. The samples were fixed with silver paste on a substrate holder located $7 \mathrm{~cm}$ away from the target. During deposition, the surface temperature of the sample was not controlled. Nevertheless, the maximum value reached during deposition was evaluated to be lower than $100^{\circ} \mathrm{C}$

The film thickness and the surface morphology were determined by scanning electron microscopy (SEM, Carl Zeiss supra-40 FEG-SEM) by using the secondary electron mode detection. The film composition was studied by energy dispersion spectroscopy (EDS, Brucker XFlash Detector 4010 coupled with the SEM) and by Rutherford Backscattering Spectroscopy (RBS) using a $2000 \mathrm{keV}^{4} \mathrm{He}^{+}$ion beam from a Van de Graff accelerator (CEMHTI laboratory). RBS is used to evaluate the global composition of heavy elements of thin films. However, the molar mass of zirconium and yttrium are too close to be discriminated by RBS. EDS is thus used to estimate the ratio between zirconium and yttrium. RBS spectra were simulated with the SIMNRA software [14]. For thick films, RBS techniques can not be used and only EDS measurements were carried out. EDS is not accurate to measure the concentration of light elements such as oxygen. Nevertheless, for thin films (less than $1 \mu \mathrm{m}$ thick), we have evidenced that the oxygen amounts estimated by EDS and RBS are very close to each others. The relative precision of oxygen concentration is estimated to be around 5\%. Finally, the control of phases and their preferred orientation regarding the surface substrate was performed by $\theta-2 \theta \mathrm{X}$-Ray Diffraction (XRD) using the $\mathrm{Cu} \mathrm{K} \alpha$ radiation $(\lambda=1.54056 \AA)$ in the $25^{\circ}-62^{\circ} 2 \theta$ range.

First, $20 \mathrm{~mm} \times 20 \mathrm{~mm} \mathrm{Si}(100)$ wafers were used as reference substrate. Silicon substrates are ultrasonically cleaned in ethanol and acetone, still presenting the native oxide. In a second step, YSZ thin films were deposited on a ultrasonically cleaned commercial NiO-YSZ anode supplied by InDec. 


\section{Results and discussion}

For growing crystalline films, it can be used a high substrate temperature allowing to improve the surface mobility of the species reaching the substrate. A high substrate temperature can be easily applied in PLD experiments while our RMS device is not equipped with a heated substrate holder making impossible the growth at high temperatures. For better comparison purpose, RMS films have been annealed in air atmosphere at $600^{\circ} \mathrm{C}$. Nevertheless such annealing process performed on the RMS thin film was found to have no influence on the film characteristics. Superficial and cross-sectional morphology, crystalline phase and chemical composition were exactly the same before and after annealing. This indicates that as-deposited RMS films are very stable under oxidizing conditions. Stability in oxidizing atmosphere is one of the well known properties of YSZ [15]. Thus, in the following, as-deposited RMS and PLD thin films will be presented and compared.

According to SEM experiments both in top view and cross section, the surface of YSZ films grown by PLD is very smooth (Fig. 1a). The grain boundaries between crystallites are not visible. Only few particles corresponding to droplet formation are evidenced. The view in cross section (Fig 1b) shows a close compact columnar structure with $100 \mathrm{~nm}$ width columns. The total thickness of the film is around $430 \mathrm{~nm}$ after $3 \mathrm{~h}$ deposition time. The deposition rate is therefore in agreement with typical values reported for PLD oxide films [16-17]. SEM images of RMS films highlight a different morphology: a rough surface composed by angularshaped structures (few hundreds of nanometer) (Fig. 2a). The film thickness is $2.5 \mu \mathrm{m}$ after a time of deposition of 10 min (Fig. 2b). The obtained deposition rate is classical of RMS experiments and is two orders of magnitude higher than that of PLD one, in the present experimental conditions. RMS films are characterized by a columnar structure. However, it 
can be noticed that the columns are better defined than for PLD films. Their width is around $100 \mathrm{~nm}$. The fracture occurs mainly between the columns which do not evidence a cylindrical shape but rather an angular morphology.

The differences observed on surface morphology of PLD and RMS films depending on the deposition technique, may be explained by the difference in the energy of particle impinging onto the surface and the surface temperature. The energy of the atoms reaching the substrate, sputtered from the magnetron sputtering target, is calculated by the SIMTRA software [18]: in our conditions, the median value of the impinging particles energy is about $4 \mathrm{eV}$ whereas the mean one is about $21 \mathrm{eV}$. In comparison, the median kinetic energy of species during the expansion of plasma plume in PLD is around several tenths of eV [19-20]. Moreover, magnetron sputtering process is carried out at high pressure and low temperature leading to a lower energy supplied to the growing film. PLD films are grown at low pressure and high temperature. The high energy available during the growth in PLD induces a high surface mobility of adatoms. As a consequence the growth of homogeneous and smooth films is favoured in PLD experiments.

The composition of films has been analysed by RBS or EDS according to the thickness of films (see Experimental). Table I shows the atomic percentage of elements detected in thin films in comparison with the expected 8YSZ composition and the target ones. In addition to the expected zirconium, yttrium, oxygen and silicon elements, hafnium was detected at relatively low percentage (lower than $0.4 \%$ ). Due to similar chemical properties with zirconium, hafnium is commonly present as impurity in commercial zirconium compounds ( $1 \%$ in the target). Nevertheless, the obtained low content in the films is expected not to be efficient for modifying the properties of the YSZ films. Thereafter, hafnium content will be incorporated in the zirconium one. 
The amount of yttria $(\mathrm{x})$ in the $(1-\mathrm{x}) \mathrm{ZrO}_{2}:(\mathrm{x}) \mathrm{Y}_{2} \mathrm{O}_{3}$ solid solution which plays an important role on the ionic conductivity [7], is calculated from the $\mathrm{Zr}$ to $\mathrm{Y}$ atomic ratio $\left(\mathbf{x}=\frac{\mathbf{\%} \mathbf{Y}}{\mathbf{2} *(\mathbf{\%} \mathbf{H f}+\boldsymbol{\%} \mathbf{Z r})+\boldsymbol{\%} \mathbf{Y}}\right)$. The second parameter given in Table I is the oxygen content normalized to the sum of the metallic elements fractions ( $\mathrm{Zr}, \mathrm{Y}$ and $\mathrm{Hf}$ ). It gives some insight into the oxidation degree of the films.

The composition of PLD films is very close to the $8 \mathrm{YSZ}$ one meaning that a congruent transfer has occurred from the target to the film. The oxygen stoichiometry showed that the metallic elements are fully oxidized and the oxygen stoichiometry is reached even if the films have been grown under vacuum. This result is not in agreement with what Heiroth et al [15] have found for YSZ films deposited onto sapphire substrates by PLD $\left(\mathrm{KrF}\right.$ laser, $4 \mathrm{~J} / \mathrm{cm}^{2}$ and $600^{\circ} \mathrm{C}$ ). These authors evidenced that for oxygen pressures lower than $1 \mathrm{~Pa}$, films are oxygen deficient. They attributed this effect to a dynamical laser induced oxygen deficiency of the target. It seems that in our conditions, by using a lower fluence $\left(2 \mathrm{~J} / \mathrm{cm}^{2}\right)$, the metallic flux coming from the target is weaker, which allows recovering the expected stoichiometry even at lower oxygen pressure (vacuum).

Due to an excess of yttrium in the RMS target, the as-deposited RMS films are Y- enriched as the composition of the target is replicated in the coating. In Table I, it can be seen that the oxygen atomic percentage is slightly lower for RMS film than the expected one; but the value stays in the confidence limit of the EDS technique. However, when calculating the oxygen ratio normalized to the sum of metallic elements fractions, it appears that this film is not fully oxidized. This is not surprising, since the deposition process was carried out in the metallic mode in order to achieve high deposition rate. Nevertheless, whatever the deposition technique used, the films are well oxidized and the yttria doping level lies in the range required to ensure maximum ionic conductivity [7]. 
The diffraction patterns corresponding to the PLD and RMS films are presented in Fig 3a and $3 \mathrm{~b}$, respectively. XRD diagrams of YSZ thin films obtained by the both techniques can be indexed by the cubic phase of the solid solution of yttria in zirconia (JCPDS 30-1468). Table II gathered the relative intensity of (111), (002), (220) and (311) diffraction lines. The intensities $\mathrm{I}_{\mathrm{JCPDS}}$ of the main diffraction planes of $\mathrm{Y}_{0.15} \mathrm{Zr}_{0.85} \mathrm{O}_{1.93}$ is given from the JCPDS file as reference for polycrystalline material without preferred orientation of the crystallites. In the case of RMS and PLD films, the preferred orientation of crystallites (calculated in \%) is determined the I'/ $\Sigma$ I' ratios, I' being the $\mathrm{I} / \mathrm{I}_{\mathrm{JCPDS}}$ ratios and $\Sigma \mathrm{I}$ ' the sum of the intensity ratios of the diffraction peaks. The obtained values evidence a (111) preferred orientation of the crystallites of the PLD and RMS films. Whatever the obtained films studied, the (200) and (220) orientation remain very weak. The fraction of crystallites with the (hkl) plane parallel to the substrate surface was evaluated from the data displayed in Table II. The PLD film presents a nearly perfect (111) out-of-plane orientation (91\%) and the RMS coating a (111) preferential orientation, with the (311) orientation being not negligible (34\%).

The grain size calculated from the Scherrer formula for the major (111) diffraction peak reached a value of $48 \mathrm{~nm}$ for RMS coating whereas the grain size of PLD coating is twice lower (about $25 \mathrm{~nm}$ ).

If we refer to Mahieu et al. work [21] on YSZ thin films using the structure zone model formalism, a (111) preferential orientation is attributed to a growth process that takes place in the zone II. This means that sufficient energy is brought to the surface during deposition so that the columns grow with the plane of lower surface energy parallel to the substrate [22]. In the case of cubic YSZ, this corresponds to the (111) plane. The fact that PLD film is perfectly (111) oriented indicates that the energy transferred to the surface is higher. 
The structural and morphological investigations on YSZ films grown by PLD and RMS on silicon single crystal show that both techniques are valuable to produce high quality YSZ thin films which look dense and on which no pinholes have been found. Their composition is close to $8 Y S Z$, and they exhibit a cubic structure with a (111) preferred orientation.

If a silicon substrate has been useful to determine the relevant parameters for growing good quality YSZ films by PLD and RMS, such support is not a suitable for most of the possible applications. In the case of SOFC- based the YSZ electrolyte requires to be deposited on a true anode material. A commercial $(\mathrm{Ra}=2.4 \mu \mathrm{m}) \mathrm{NiO}-\mathrm{YSZ}$ anode supplied by InDec was chosen as an example of a porous and rough support. $1 \mu \mathrm{m}$-thick PLD ( $8 \mathrm{~h}$ deposition time) and $2 \mu \mathrm{m}$-thick (10 min deposition time) RMS coatings were deposited in the previously used deposition conditions.

Whatever the deposition techniques used, large scale SEM top views expose that the film deposited on the anodes presented no pinholes. Furthermore no rupture can be evidenced on SEM cross-section images after cleaving (Figure 4). The observations in cross-section show that the PLD and RMS coatings followed the surface roughness of the substrate. However, the surface morphology was very different: since the PLD film is smooth, it replicates the granular shape of the anode surface, whereas the RMS film roughness partly overlaps the grain structure of the substrate. The RMS film was angular shaped like the film surface morphology observed on silicon (Figure 2).

The columnar morphology of RMS coatings was again better distinguishable compared to PLD coatings. The synthesis of dense and featureless YSZ thin films by PLD on NiO-YSZ substrates has already been reported [23]. On the contrary, well defined columns were evidenced on the YSZ film grown by RMS as reported by Briois et al. [11]. Our results are thus in good agreement with very few available works dedicated to these kinds of thin films 
for SOFC application. They prove that PLD and RMS techniques are both interesting techniques for further development of YSZ films (in the thickness range 0.1 to $10 \mu \mathrm{m}$ ) even when rough supports are required for the application.

\section{Conclusion}

Yttria-stabilized zirconia (YSZ, $\mathrm{ZrO}_{2}: \mathrm{Y}_{2} \mathrm{O}_{3}$ ) was deposited on (100) silicon by pulsed-laser deposition carried out in vacuum from a ceramic target and by direct current reactive magnetron sputtering from a $\mathrm{Zr} / \mathrm{Y}$ metallic target in reactive atmosphere. PLD produces dense and structureless films in the cubic phase with a strong orientation of crystallites according to the (111) plane parallel the surface substrate. The oxygen stoichiometry of PLD films is preserved while a slight depletion in yttrium is observed. In the used experimental conditions, the deposition rate is around $130 \mathrm{~nm} / \mathrm{h}$. Reactive magnetron sputtering produces columnar but compact thin films at high deposition rate $(15000 \mathrm{~nm} / \mathrm{h})$. Even if the growth has been performed at low temperature (around $100^{\circ} \mathrm{C}$ ), the films are well crystallised and display a preferred (111) orientation. The composition of films is found to be oxygen deficient but the global amount of metallic element is in the expected range to get a good ionic conductivity. Compact crystalline YSZ films were successfully obtained on a commercial porous support with both techniques. The films are adherent and were found to efficiently fill the substrate porosity, which is required for SOFC application that was discussed in this paper. Thus it seems that PLD and RMS are promising ways to produce YSZ thin films used as SOFC electrolyte. However, properties such as ionic conductivity should be tested to complete this first study that only focused on the morphological, chemical and structural features of the films. The slight differences observed between both films according to their structural and 
morphological properties and their composition are expected to be useful to tailor the ionic conductivity regarding the growth method used.

\section{Acknowledgment}

The authors greatly acknowledge Dr D.Damiani of CEA Le Ripault (Mons, FRANCE) for supplying the anodes. The "Région CENTRE" is also acknowledged for its financial support from the APR ELECTROLYTE and the E. Reguzina's fellowship. 


\section{Reference}

[1] N. Savvides, S. Gnanarajan, Physica C: Superconductivity, 387, (2003) 328-340

[2] S.H. Jeong, I.S. Bae, Y.S. Shin, S.-B. Lee, H.-T. Kwak, J.-H. Boo, Thin Solid Films 475 (2005), 354-358

[3] S. Radice, P. Kern, G. Bürki, J. Michler, M. Textor, Journal of Biomedical Materials Research Part A 82A (2007) 436-444

[4] L. Vanni, S. Valte, Dental Materials, 26 (2010) 807-820

[5] N. P. Padture, M. Gell, E. H. Jordan, Science 296 (2002) 280-284

[6] J. Gao, J.P. Viricelle, C. Pijolat, P. Breuil, Ph. Vernoux, A. Boreave, A. Giroir-Fendler, Sensors and Actuators B: Chemical, In Press, Corrected Proof available online 6 February 2010

[7] J. W. Fergus, J. Power Sources 162 (2006) 30-40

[8] D. Beckel, A. Bieberle-Hutter, A. Harvey, A. Infortuna, U.P. Muecke, M. Prestat, J.L.M. Rupp, L.J. Gauckler, J. Power Sources 173 (2007) 325-345

[9] K. C. Wincewicz, J. S. Cooper, J. Power Sources, 140 (2005) 280-296

[10] K. Rodrigo, J. Knudsen, N. Pryds, J. Schou, S. Linderoth, Appl. Surf. Sci. 254 (2007) 1338-1342]

[11] P. Briois, A. Billard, Surf. Coat. Technol. 201 (2006) 1328-133

[12] E. Millon, J. Perrière, W. Seiler, R. Benzerga, and C. Boulmer-Leborgne, J. Crystal Growth, 311 (2009) 3352-3358

[13] E. Rezugina, A.L. Thomann, H. Hidalgo, P. Brault, V. Dolique, Y. Tessier, Surf. Coat. Technol., 204 (2010) 2376-2380

[14] M. Mayer, K. Arstila, K. Nordlund, E. Edelmann, and J. Keinonen, Nucl. Instr. Meth. B249 (2006) 823

[15] S. Heiroth, T. Lippert, A. Wokaun, M. Dobeli, J.L.M. Rupp, B. Scherrer, L.J. Gauckler, J. Eur. Ceram. Soc. 30 (2010) 489-495

[16] D.B. Chrisey, G.K. Hubler (Eds.), Pulsed Laser Deposition of Thin Films, Wiley, New York, 1994

[17] N. Sbai, J. Perriere, W. Seiler, E. Millon, Surf. Sci. 601 (2007) 5649-5658

[18] K. Van Aeken,S. Mahieu, D. Depla, J. Phys D: Appl. Phys. 41 (2008) 205307-205313

[19] E. Millon, J. Perriere, R.M. Defourneau, D. Defourneau, O. Albert, J. Etchepare, Appl. Phys. A 77 (2003) 73-80

[20] J. Hermann, C. Vivien, A. Caricato, C. Boulmer-Leborgne, Appl. Surf. Sci. 127-129, (1998) 645-649

[21] S. Mahieu, P. Ghekiere, D. Depla, R.D. Gryse, Thin Solid Films 515 (2006) 1229-1249 
[22] S. Mahieu, P. Ghekiere, G.D. Winter, D. Depla, R.D. Gryse, O. Lebedev, G.V. Tendeloo, Thin Solid Films 484 (2005) 18-25

[23] B. Hobein, F. Tietz, D. Stöver, E.W. Kreutz, J. Power Sources 105 (2002) 239-242

Voir directement dans le texte 


\section{Tables}

Table I: atomic concentrations, yttria doping and oxygen to metallic element ratio measured for PLD and RMS films. The composition of the targets and the expected 8YSZ one is given as reference.

\begin{tabular}{|c|c|c|c|c|c|}
\cline { 2 - 6 } \multicolumn{1}{c|}{} & \multirow{2}{*}{\multicolumn{1}{c|}{8 YSZ }} & Target & As deposited & target & As deposited \\
\cline { 2 - 6 } \multicolumn{1}{c|}{} & 29.1 & 29.8 & 28.6 & 77.8 & 30.9 \\
\hline $\mathrm{Zr}$ & 5.1 & 4.7 & 5.0 & 21.2 & 7.9 \\
\hline $\mathrm{Y}$ & 65.8 & 65.0 & 66.4 & - & 60.9 \\
\hline $\mathrm{O}$ & - & 0.5 & 0.4 & 1.0 & 0.3 \\
\hline $\mathrm{Hf}$ & 8.0 & 7.2 & 7.9 & 11.9 & 11.2 \\
\hline $\mathrm{X}$ & 1.93 & 1.86 & 1.95 & - & 1.56 \\
\hline $\mathrm{O} /(\mathrm{Zr}+\mathrm{Hf}+\mathrm{Y})$ & & & & & \\
\hline
\end{tabular}


Table II: Normalised intensities I (\%), I/IJCPDS ratios (noted I'), preferred orientations calculated from the I'/ $\Sigma$ I' ratios and FWHM of the (hkl) diffraction planes measured on the PLD and RMS films

\begin{tabular}{|c|c|c|c|c|c|c|c|c|c|}
\hline \multirow[b]{2}{*}{ (hkl) } & 8YSZ bulk & \multicolumn{4}{|c|}{ RMS film } & \multicolumn{4}{|c|}{ PLD film } \\
\hline & $\mathrm{I}_{\mathrm{JCPDS}}(\%)$ & $\begin{array}{c}\mathrm{I} \\
(\%)\end{array}$ & $\begin{array}{c}I^{\prime}= \\
I^{\prime} I_{\text {JCPDS }}\end{array}$ & $\mathrm{I}^{\prime} / \Sigma \mathrm{I}^{\prime}$ & $\begin{array}{c}\text { FWHM } \\
\left({ }^{\circ}\right)\end{array}$ & I (\%) & $\begin{array}{c}\mathrm{I}^{\prime}= \\
\mathrm{I} / \mathrm{I}_{\mathrm{JCPDS}}\end{array}$ & $\mathrm{I}^{\prime} / \Sigma \mathrm{I}^{\prime}$ & $\begin{array}{c}\text { FWHM } \\
\left({ }^{\circ}\right)\end{array}$ \\
\hline 111 & 100 & 100 & 1 & $44 \%$ & 0.40 & 100 & 1 & $91 \%$ & 0.21 \\
\hline 200 & 25 & 6.5 & 0.26 & $11 \%$ & 0.20 & - & - & - & - \\
\hline 220 & 55 & 12 & 0.22 & $9 \%$ & 0.52 & 1 & 0.02 & $2 \%$ & 0.36 \\
\hline 311 & 40 & 31 & 0.77 & $34 \%$ & 0.20 & 3 & 0.07 & $6 \%$ & 0.31 \\
\hline & & & $\begin{array}{l}\sum I^{\prime}= \\
2.25\end{array}$ & & & & $\begin{array}{l}\Sigma \mathrm{I}^{\prime}= \\
1.09\end{array}$ & & \\
\hline
\end{tabular}




\section{List of figure captions}

Figure 1: SEM micrographs of YSZ films grown by PLD on (100) Si substrate at $500^{\circ} \mathrm{C}$ under $10^{-4} \mathrm{~Pa}$ : a) top view, b) cross-section

Figure 2: SEM micrographs of YSZ films grown by RMS on (100) Si substrate at room temperature under $1 \mathrm{~Pa}$ : a) top view, b) cross-section

Figure 3: $\theta-2 \theta$ XRD diagrams: a) YSZ film grown by PLD on Si substrate at $500^{\circ} \mathrm{C}$ under $10^{-}$

${ }^{4} \mathrm{~Pa}$ b) YSZ films grown by RMS on Si substrate at room temperature under $1 \mathrm{~Pa}$

Figure 4: YSZ thin films grown onto NiO-YSZ: a) PLD films: top view (left) and cross section (right), b) RMS films: top view (left) and cross section (right) 


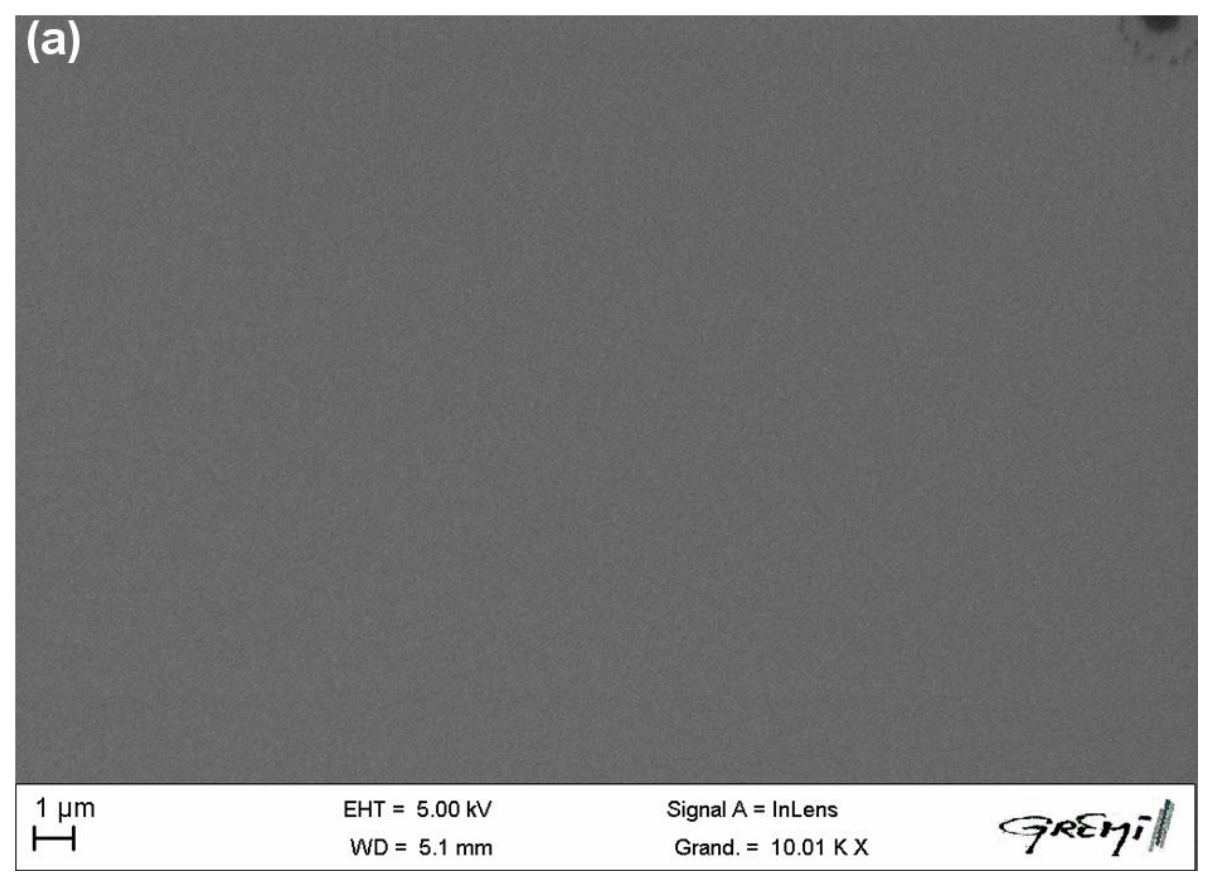

(b)

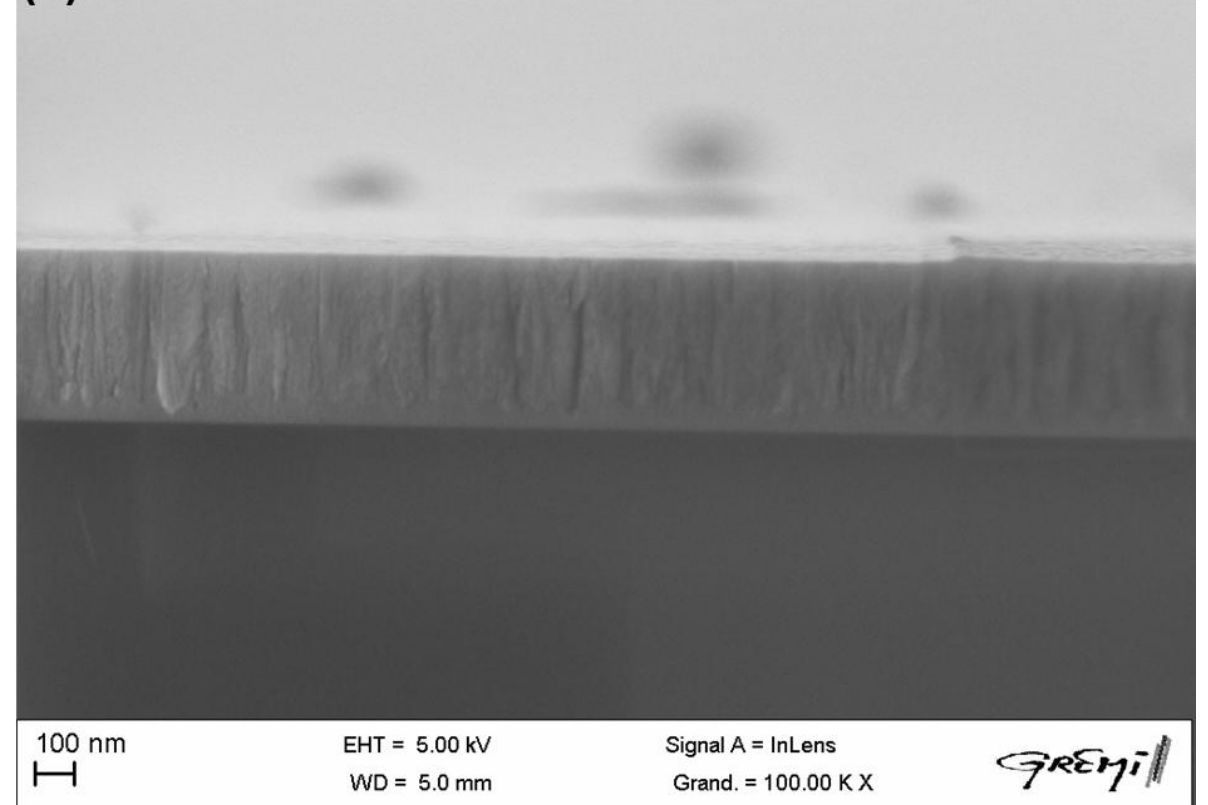

Fig. 1 

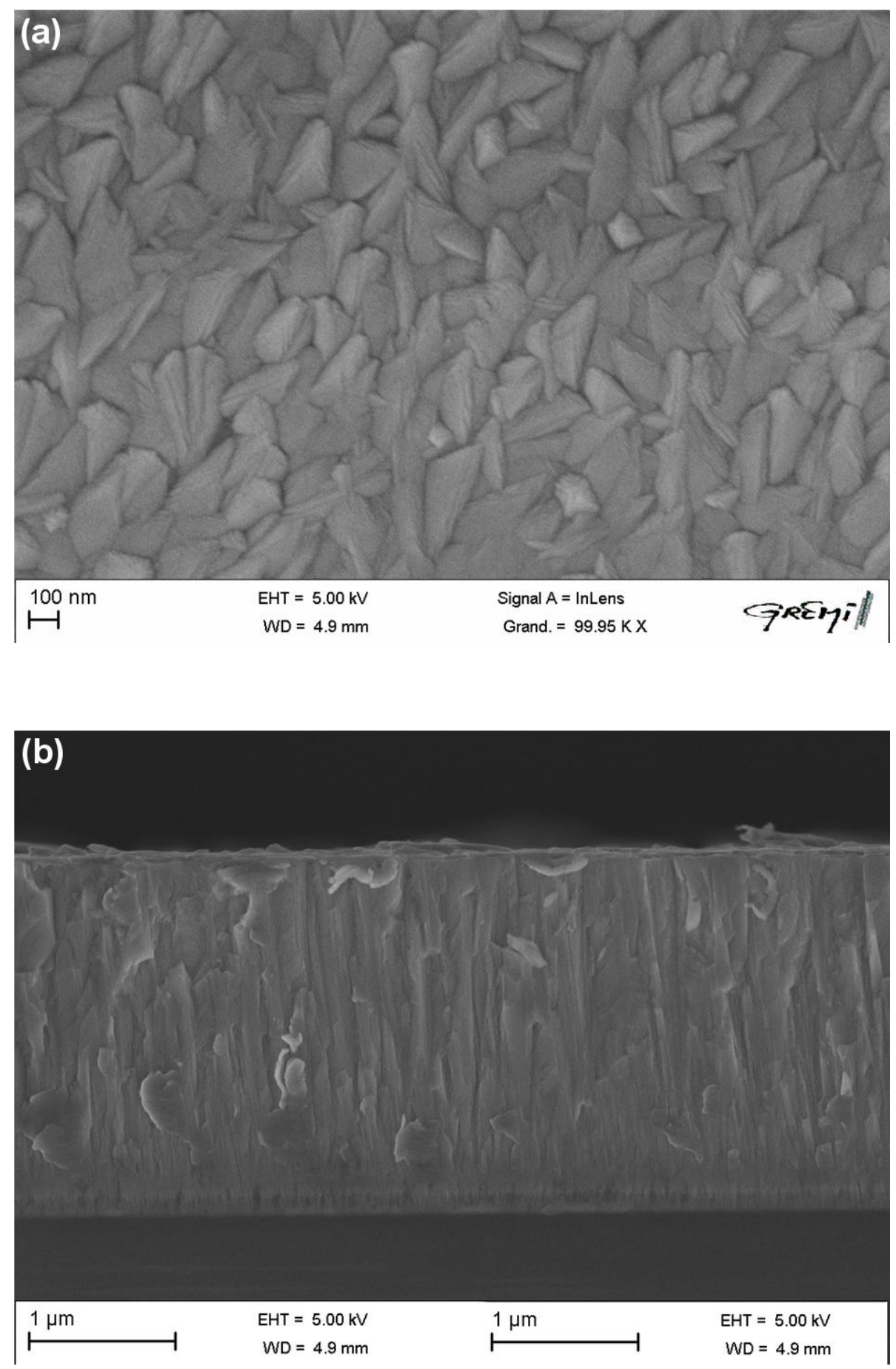

Fig 2 

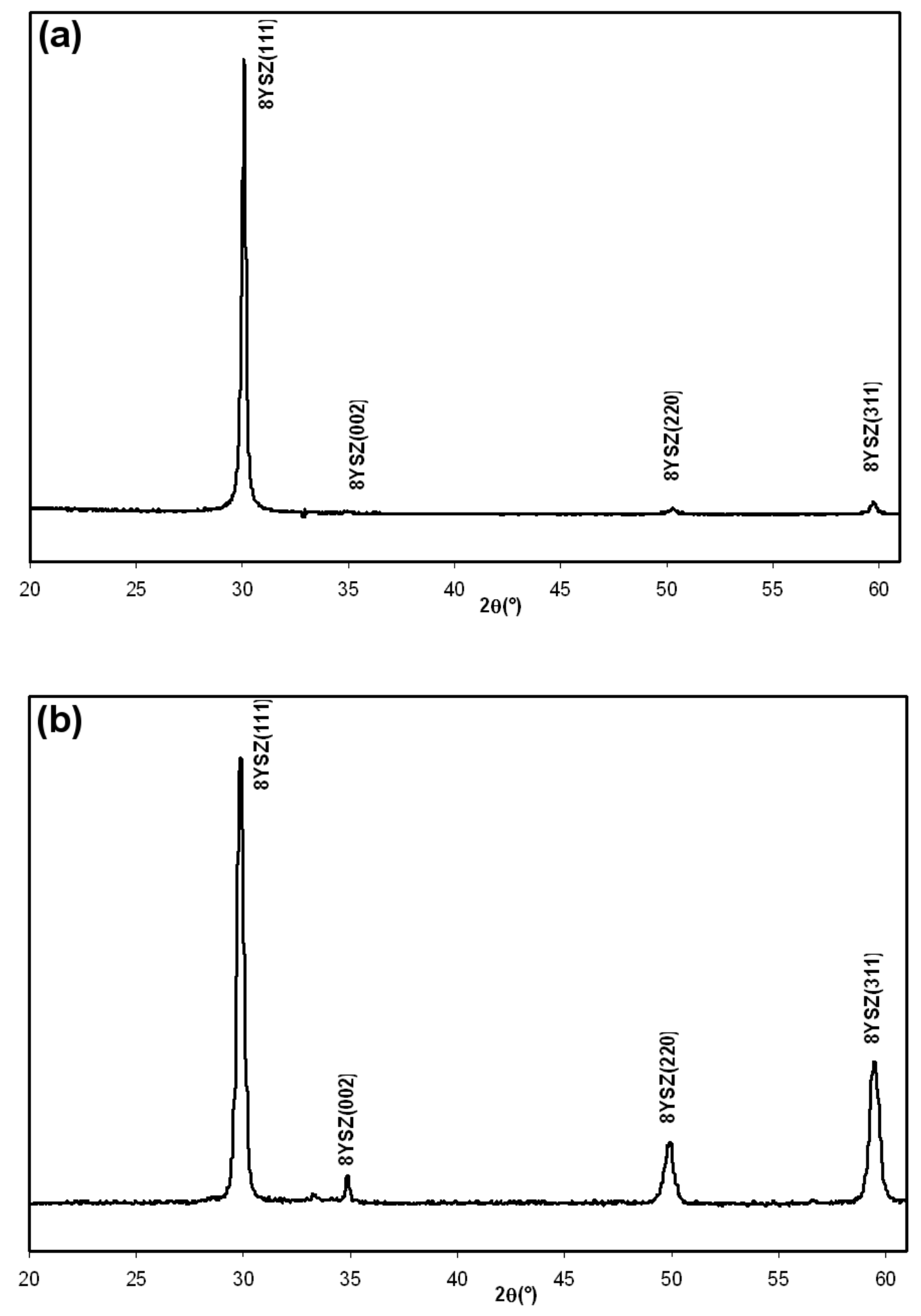

Fig 3 

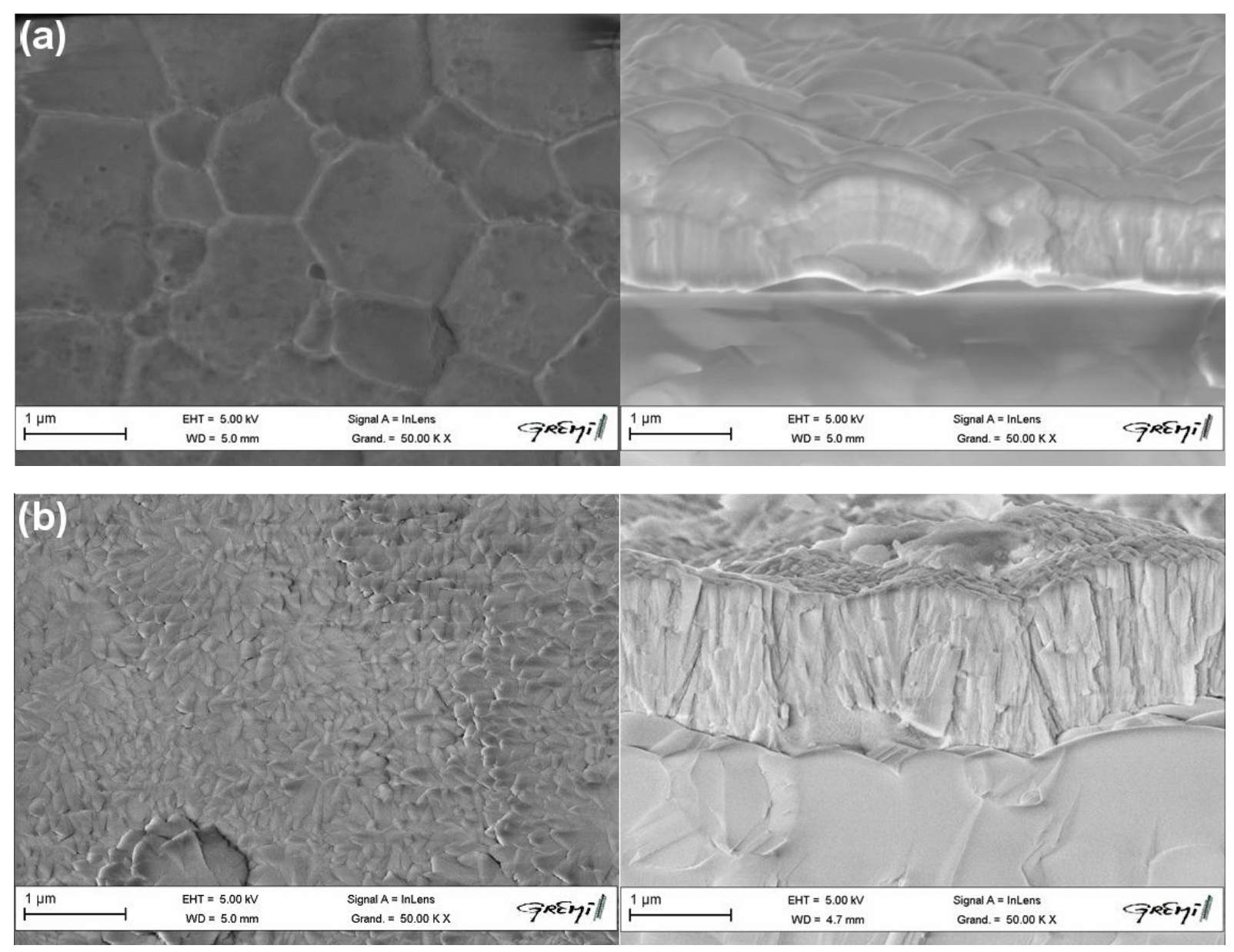

Fig 4 